\title{
Knowledge and Attitude on STDs and HIV and AIDS among Secondary School Students
}

\author{
Basanta Kumar Baral, Lecturer \\ Kathmandu Shiksha Campus
}

\begin{abstract}
The study was carried out to find out the knowledge and attitude on STDs and HIV and AIDS among Secondary School students of Kathmandu District. This study followed the simple random sampling method to select the respondents. Altogether 120 adolescents were the respondents of the study and questionnaire and attitude scale were was the tools of the study. The study found that, 25 percent answered full form of STDs and HIV and AIDS correctly. Almost 50 percent of the respondents had knowledge about commercial sex workers who had high risk of STDs and HIV transmission. Similarly, 62.5 percent respondents who answered sex education is needed and same percent expressed condom is one of the most important device that protect STDs and HIV and AIDS transmission. Premarital and extra marital sex may cause STDs and HIV and AIDS was responded as 25.00, 23.33, 18.33, 30.00 and 3.33 percent as strongly agreed, agreed, undecided, disagreed and strongly disagreed respectively. In the statement 'students must get proper sexual and reproductive health from junior to higher education' to prevent and control HIV and AIDS and other STDs and 30.00, 23.33, 15.00, 8.33 and 23.33 percent respondents agreed, undecided, disagreed and strongly disagreed respectively. It seems that respondents were deprived to get proper knowledge on STDs and HIV and AIDS. Hence, government must monitor schools whether they are providing SRH properly or not and also government must appoint the concern academic background HPE Ed. teacher to teach SRH matter properly.
\end{abstract}

Keywords: Adolescent, vulnerable, injecting drug, transmission, premarital, extramarital, commercial sex etc.

\section{Introduction}

Acquired immune deficiency syndrome (AIDS) is the emerged serious public health problem throughout the world. STDs and HIV and AIDS is one of the main human immunodeficiency virus of retro-virus group which slowly destroys the human body immune system (Oli, 2005). Till the date STDs especially HIV and AIDS is known as life threatening incurable disease. 
According to U.S. department of health and human services, in the United States more than 13 million people are infected each year and more than 65 million have an incurable STDs (UN AIDS, 2003). The global statistics published by UN AIDS (2011) showed that nearly 39.5 million have been living with HIV and AIDS since 1981. Since the STDs and HIV and AIDS epidemic began, almost 58 million people throughout the world have been infected with HIV and almost 22 million people have died. More than 90 percent of new infections and 89 percent of deaths occurring in substance African and south East Asian countries and estimated 16,000 people are becoming newly infected with HIV each day (WHO, 2009). Adolescent; spanning between the ages 10 to 19 years, is a period of transition from childhood to adulthood. This period is highly vulnerable to sexually transmitted diseases due to the physiological changes and lack of knowledge about physiological changes and their proper management, adolescents may involve in unsafe sexual activities. Hence, adolescents may be the key agent to aware and control the HIV and AIDS and other sexually transmitted infections through peer approach.

Adolescent and youth are most vulnerable group among the total population. They are backbone of the society and have no sufficient knowledge about STDs and HIV and AIDS . There is no effective programme, which can make the people aware and play vital role to prevent from STDs and HIV and AIDS. Hence, it is difficult to mitigate STDs and HIV and AIDS as targeted by the NCASC and the government. The first case of AIDS in Nepal was reported in 1988. In 2012, national estimates indicated that approximately 70,000 adults and children are infected with the HIV in Nepal with an estimated prevalence of 0.49 percent in the adult population (MOHP, 2012). A total of 55627 HIV positive cases have been reported by the national centre for AIDS and STDs control (NCASC) in 2011 with 0.33 percent prevalence rate the. Although the cases are decreasing gradually, STDs and HIV and AIDS problem have been deep rooted mostly in developing country, Nepal is a developing country. So it is not isolated from this problem. The first HIV positive case in Nepal was diagnosed in July 1988. The increase rate of HIV positive was low by late 1996. In 1996, this number reached to 135 , in 1997, this number rapidly rose to 489 (NCASC, 2011). According to CBS (2063 BS) there are 46309 drug abuser in Nepal and out of them 98.2 percent are male. Likewise, CBS further said that total 66 percent are below the age of 25 and out of them 61 percent are injecting drugs who are highly vulnerable to HIV and STDs.

This research is directly based on school adolescents; it is helpful to know about the level of knowledge and attitude, views on STDs and HIV and AIDS among students of secondary level. The finding of this study may help to the policy makers and persons 
working in the field of STDs and AIDS prevention. It would be the guideline to know the knowledge and attitude of adolescents of STDs and HIV and AIDS problems and to implement some of the effective programs. The general objective of the study was to find out the knowledge and attitude on STDs and HIV and AIDS among Secondary School students of Kathmandu District. The specific objectives were: to examine the knowledge on STDs and HIV and AIDS of school adolescents, to identify school adolescents perspectives towards STDs and HIV and AIDS and to identify the attitude of school adolescents toward STDs and HIV and AIDS .

\section{Methodology}

This study followed descriptive research design which attempts to study the knowledge and attitude on STDs and HIV and AIDS . This study mainly based on primary source of data. Data were collected from the selected secondary level students. This research included the students of secondary level, of Chabahil area of Kathmandu valley. Thus all secondary level students studying in community run schools of Chabhil Mitrapark area were the population of the study. From grade (8-10), a total of 120 students, 40 boys from each grade were selected randomly by using lottery method. Questionnaire and attitude scale were designed to collect the necessary information in knowledge and attitude on STDs and HIV and AIDS of the respondents. For pre-test, questionnaire was administered on 20 secondary level students of Chagal secondary school and on the basis of the result of pretest questionnaire was finalized.

First of all, approval was taken with the head teacher then visited to the EPH teacher and requested to help for the administered the questionnaire and the attitude scale. Then set of questionnaires and attitude scale were provided to the already selected boys students of grade 8,9 and 10 with necessary instruction. The respondents were carefully supervised during the distribution of tools to minimize possible error. This process was done separately for class 8,9 and 10 .

\section{Result and discussion}

Data were analyzed and interpreted manually. The quantitative information were analyzed and interpreted and explained in detail. Possible discussion was added to clarify the collected information from the respondents.

In present days STDs, HIV and AIDS and hepatitis B are the burning sexually transmitted infections. Many people are dying of these infections every year and these are the challenging public health problems to the present society. Other common types of STIs are syphilis, gonorrhea, sanchroid, white discharge from vagina, PID, lower abdominal pain etc. In this context respondents were asked various questions related to 
knowledge about HIV and AIDS and attitude towards them. According to the response of the respondents only 25 percent became able to tell the full form of STDs and HIV and AIDS Correctly. Many of them ignored about it. Only 20 percent of the respondent were able to tell the actual difference between STDs and HIV and AIDS . Among all respondents, 7.55 percent replied by untested blood transfusion, and 15 percent by using un-sterilized needles or other instruments caused HIV and AIDS and STDs. Similarly, 50 percent of the respondents had given the answer; commercial sex workers are at the high risk of STDs and HIV transmission.

Among all respondents 30 percent answered not to have sex with multiple partners, 17.5 percent expressed to use condoms during sexual intercourse, 25.5 percent answered that self-discipline in sexual habit is a good way to prevent from infection. Study shows that majority of the respondents $(62.55 \%)$ had given their view against love and affection for HIV infected persons, 12.5 percent accepted sexual intercourse before marriage. They expressed that it is not bad to do safe and healthy sexual intercourse. Among all, 62.5 percent respondent who answered sex education is needed for adolescents. Among all 62.5 percent expressed condom is one of the most important device that protect STDs and HIV and AIDS transmission.

The attitude towards STDs and HIV and AIDS was measured on the basis of Likert Scale. The first option (strongly agree) indicates that adolescents were highly willingness to the attitude measures at statements. The second one (agree) represents that the respondents were willingness with the statements in attitude measure scale, third option (neutral/indifference) means respondent did not discriminate the statements about STDs and HIV and AIDS . Likewise, fourth (disagree) shows the respondents' were unwillingness about the statements in attitude scale and last (strongly disagree) represents the completely unwillingness of the respondents about the statement in attitude scale.

In attitude scale; STDs and HIV and AIDS are caused due to past deeds was given at first and in this statement no one were strongly agreed and only $0.83 \%$ were agreed with the statement. STDs and HIV and AIDS are caused due to transfusion of untested blood was strongly agreed by 33.33 percent of the respondents and 37.5 percent were agreed. In the context of premarital and extra marital sex may cause STDs and HIV and AIDS and respondents responded by 25.00, 23.33, 18.33, 30.00 and 3.33 percent as strongly agreed, agreed, undecided, disagreed and strongly disagreed respectively. Regarding the statement commercial Sex workers are vulnerable to STDs and HIV and AIDS and in this statement only 6.67 percent strongly disagreed. In the statement common toilet and shaking hands do not spread STDs and HIV and AIDS 34.17, 4.16, 
8.33, 25.83 and 27.5 percent were strongly agreed, agreed, undecided, disagreed and strongly disagreed respectively. About 28.33, 15.00, 28.33, 19.17 and 9.6 percent of the respondents were strongly agreed, agreed, undecided, disagreed and strongly disagreed with the statement proper counseling and moral spiritual support must be given to the STDs and HIV and AIDS infected person'. In the statement 'Students must get proper sexual and reproductive health from basic to higher education' and 30.00, 23.33, 15.00, 8.33 and 23.33 percent respondents were agreed, undecided, disagreed and strongly disagreed respectively.

\section{Conclusion}

On the basis of the analysis and interpretation it can be concluded that respondents were deprived to get the proper sexual and reproductive health education. Still some of the students have negative attitude about sexual and reproductive health. Respondents had mixed type of attitude on STDs and HIV and AIDS which mean respondents were lacking proper knowledge on STDs and HIV and AIDS . Hence, government must monitor schools whether they are providing sexual and reproductive health (SRH) properly or not and also government must appoint the concern academic background HPE Ed. teacher to teach SRH matter properly which will mitigate the chances of being infected from STDs and HIV and AIDS .

\section{References}

Central Bureau of Statistics (CBS) (2063). A survey of teenagers in Nepal for life skills development and STDs and HIV and AIDS prevention in Nepal. Kathmandu: Author.

Ministry of Health and Population (MOHP) (2012). Nepal health survey report 2012. Kathmandu: Author.

National Center for AIDS and Sexually transmitted Disease Control, (2011). Cumulative STDs and HIV and AIDS situation of Nepal. Kathmandu: Author.

Oli, P. (2005). Prospectus on STDs and HIV and AIDS, population magazine. Kathmandu: Sunaulo Prakashan.

United Nations Program on HIV and AIDS (UNAIDS) (2003). STDs and HIV and AIDS and young people; hope for tomorrow. Geneva: Author.

United Nations Program on HIV and AIDS (UNAIDS) (2011). UNAIDS fact sheet. Retrieved from http://.UN AIDS.org on 21st August, 2016.

World Health Organization (WHO) (2009). Protecting youths from STDs and HIV and AIDS : A manual for adolescents and their families. New Delhi: Author. 